\title{
Hiperrealitas Fotografi Jurnalistik
}

\author{
Nico Kurnia Jati \\ Program Magister Penciptaan Seni Fotografi, \\ Institut Seni Indonesia, Yogyakarta, Indonesia \\ E-mail: nicokurnia401@gmail.com
}

\begin{abstract}
Abstrak
Fotografi jurnalistik menjadi seni pendokumentasian dan pengarsipan yang mengandung nilai berita sehingga penayangannyapun harus berdasar pada nilai realitas yang ada. Editing yang berlebihan di meja redaktur foto dapat merubah unsur realitas yang ada sehingga dapat mengakibatkan terhambatnya pesan yang akan disampaikan kepada khalayak, oleh karena itu foto jurnalistik harus selalu mengedepankan unsur realitas sebagai pertanggungjawaban fotografer, redaktur dan media kepada masyarakat agar tidak menggiring opini yang multi interpretatif.
\end{abstract}

Kata kunci: Foto Jurnalistik, Realitas, Media, Editing, Informasi.

\begin{abstract}
Journalistic photography is the art of documenting and archiving that is news worthy so that its broadcast must be based on the value of the existing reality. Excessive editing on the photo editor's desk can change the existing reality elements so that it can lead to obstruction of the messages that needs to be conveyed to the public. Therefore, photojournalism must always prioritize the element of reality as the responsibility of photographers, editors, and the media to the public so as not to lead multi-interpretive opinions.
\end{abstract}

Keywords: Journalistic photograph, reality, media, editing, information.

\section{Pendahuluan}

Foto jurnalistik menjadi hal yang tidak terpisahkan dalam penyampaian fakta yang berasal dari realitas kejadian sehari-hari, fotografi jurnalistik menjadi wahana alternatif penyampaian berita melalui media gambar. Fotografi jurnalistik tidak bisa dipisahkan dari kehadirian suatu isu kemanusiaan termasuk penyampaian sebuah momen yang akan menjadi fakta sejarah, oleh karena itu realitas fotografi jurnalistik tidak boleh memiliki makna ganda dan multi tafsir karena bentuk visual yang memacu pemaknaan yang berbeda.

Foto jurnalistik sebagai karya pengarsipan sejarah dalam bentuk dokumentasi dua dimensi dari sebuah realitas, harus memiliki kebenaran mutlak. Foto jurnalistik selalu dianggap sebagai medium artefak masa kini sehingga tidak boleh diutak-atik pengerjaannya, proses editing gambar dan caption-nya, pemotretannya, hingga medium cetaknya pada surat kabar harian atau media online.

Salah satu bentuk dari luasnya dunia komunikasi adalah visual foto dimana dalam sebidang gambar atau sebuah bentuk visual dapat menceritakan tentang sebuah kejadian. Foto seolah-olah bisa diajak bicara oleh orang yang melihat. Foto yang baik adalah foto yang dapat menimbulkan emosi orang yang melihat. Menurut Kamus Umum Bahasa Indonesia karangan Poerwadarminta, fotografi merupakan seni dan proses penghasilan gambar melalui film (sensor digital) atau permukaan yang dipekakan. Jenis foto sendiri sangatlah beragam dari foto jurnalistik, foto iklan, foto modeling hingga foto konsep namun semuanya hampir memiliki kesamaan yang sama yaitu dapat menceritakan dan menyampaikan sebuah keadaan, maksud, dan tujuan.

Foto memiliki pengaruh yang besar dalam dunia Jurnalistik. Sebuah visual foto memang bisa direkayasa baik dari segi gambar dan segi metadata, akan tetapi setiap media tentunya akan berlomba-lomba untuk membuat berita yang berbobot, berimbang, dan jujur, karena foto jurnalistik memiliki dampak sosial yang kuat dalam isu-isu yang berkembang di masyarakat. Bentuk media cetak yang mudah diarsipkan (kliping) membuat masyarakat khususnya penggiat foto jurnalistik menjadi tahu mana yang menampilkan visual rekayasa dan visual yang asli di lapangan sehingga setiap pewarta foto memiliki tanggung jawab sosial di balik karya yang telah dimuat. 
Fotografi merupakan bahasa gambar, hasil terakhir dari bentuk tertua komunikasi percetakan. Berbeda dengan kata-kata yang diungkapkan atau ditulis, ia adalah bentuk komunikasi yang dapat dipahami di seluruh dunia. Dalam dunia fotografi sifat utama tiap pemotretan ialah bentuk otentiknya. Gambar atau lukisan yang dibuat dari kenyataan atau kenang-kenangan biasanya tidak cermat atau tidak lengkap, yang diciptakan dari khayalan mungkin sepenuhnya tidak benar. Semua pemotretan merupakan laporan pandangan mata, sifat inilah yang menyebabkan pemotretan lebih meyakinkan daripada ribuan katakata dan memberikan kekuatan serta keyakinan yang tidak dapat ditemukan dalam bentuk komunikasi apapun (Freineger, 1999:20).

Berbagai media berlomba-lomba untuk menampilkan foto terhangatnya sebagai penghias halaman muka hingga menambah unsur dramatisasi dalam penyajian warnanya. Sudah menjadi hal yang sangat jelas jika editing foto jurnalistik hanya sebatas pada pemahaman kamar gelap saja seperti dodge, burning, croping, brightnes dan level. Akan tetapi penggunaan High Dynamic Range (HDR) hingga pencangkokan objek tidak hanya membohongi unsur realitasnya saja akan tetapi sudah mengingkar hakikat dari foto jurnalistik yang selalu menyampaikan realitas melalui media visual.

\section{Pembahasan}

Pernah terjadi pada pemberitaan surat kabar harian asal Inggris The Times edisi cetak pada 20 Februari 2014 yang memberitakan tentang tindak kekerasan oleh militer pada demonstran di kota Kiev Ukraina dengan judul halaman muka 'Bloody carnage in Kiev' dan pemberitaan The Times pada tanggal 18 Juli 2014 tentang jatuhnya pesawat MH-17 milik Malaysia Airlines yang ditembak jatuh di Wilayah Ukraina dengan judul halaman muka 'Blown out of the sky'. Kedua foto yang diambil dari kantor berita AP Photo dan Getty Images tersebut diedit ulang dengan warna yang tidak sama dengan realitas aslinya.

Sebuah foto yang terpampang dalam selembar surat kabar harian sudah menunjukan unsur $5 \mathrm{~W}$ $+1 \mathrm{H}$ ditambah lagi dengan caption yang menerangkan unsur-unsur yang tidak terlihat dalam gambar untuk semakin memperkuat nilai berita dari sebuah foto jurnalistik. Caption melalui media non visual menerangkan objek-objek yang tidak ada dalam foto sehingga orang yang melihat foto jurnalistik tersebut digiring ke dalam sebuah objektifitas informasi.
Dalam tampilan foto jurnalistik kekuatan sebuah gambar dapat menerangkan sebuah kejadian dengan menguraikan unsur-unsur pembentuk foto melalui objek-objek di dalamnya melalui prinsip $5 \mathrm{~W}+1 \mathrm{H}$ dalam sebuah foto seperti siapa yang terpampang dalam foto tersebut; kejadian apa yang tergambarkan dalam foto yang bisa diartikan aktivitas yang terlihat dalam sebuah foto; di mana kejadian tersebut, bisa dilihat dari latar belakang objek yang dapat menunjukan lokasi kejadian, kapan atau waktu terjadinya kejadian tersebut dapat dilihat dari keadaan alam sekitar yang sudah terekam dalam foto tersebut entah waktu yang menunjukkan pagi, siang, sore, atau malam hari; mengapa kejadian tersebut dapat terjadi dalam hal ini kekuatan point of interest dan kegiatan human interest disekelilingnya dapat membantu menafsirkan latar belakang peristiwa tersebut; serta bagaimana kejadian tersebut bisa terjadi dapat dirangkum dari aspek subjektivitas gambar yang memperlihatkan bentuk kejadian dari foto tersebut

Karya foto milik kontributor AP Photo, Dmitri Lovetsky yang secara realis gamblang memotret seorang petugas keamanan yang mengawasi sisasisa puing pesawat $\mathrm{MH}-17$ dengan latar belakang sinar matahari yang redup dan cenderung low light, dapat oleh redaktur The Times disulap menjadi terang benderang dan langit menjadi biru bergelombang seperti editing salon foto yang terlihat sangat mengedepankan unsur keindahan daripada unsur realitas. Realitas foto jurnalistik terlihat flamboyan jika mengedepankan unsur keindahan dan dramatisasi objek akan tetapi tidak memperhatikan batasan-batasan editing dengan dasar realitas kejadian sebenarnya di lapangan.

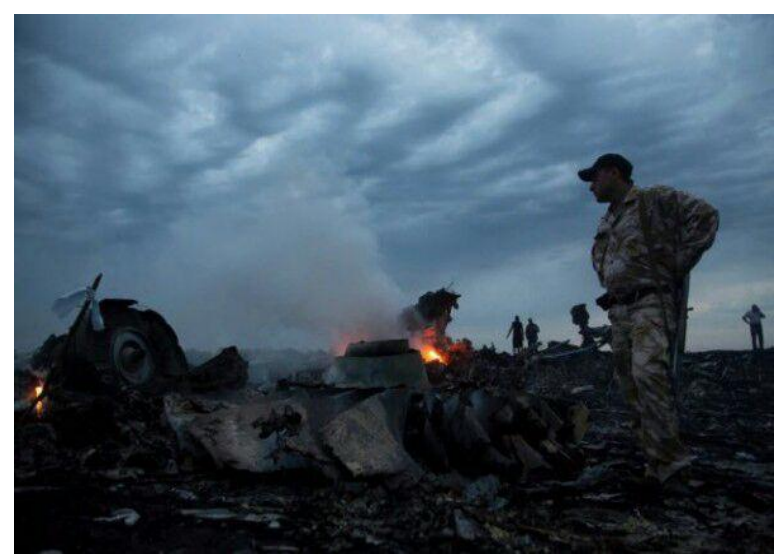

Gambar 1. Foto karya kontributor AP Photo, Dmitri Lovetsky saat belum memasuki proses editing atau masih di web AP Photo.

Setelah gambar milik kantor berita AP Photo tersebut diunduh oleh The Times dan ditampilkan pada portal berita online, gambar tidak mengalami 
banyak perubahan kecuali level dan contrast-nya sedikit dinaikkan. Hanya menambah level kontras pada foto jurnalistik masih dalam tataran wajar itupun untuk dimuat di portal berita online yang mengedepankan kecepatan update berita sehingga tidak memerlukan proses editing yang panjang demi kecepatan tersiarnya sebuat berita.

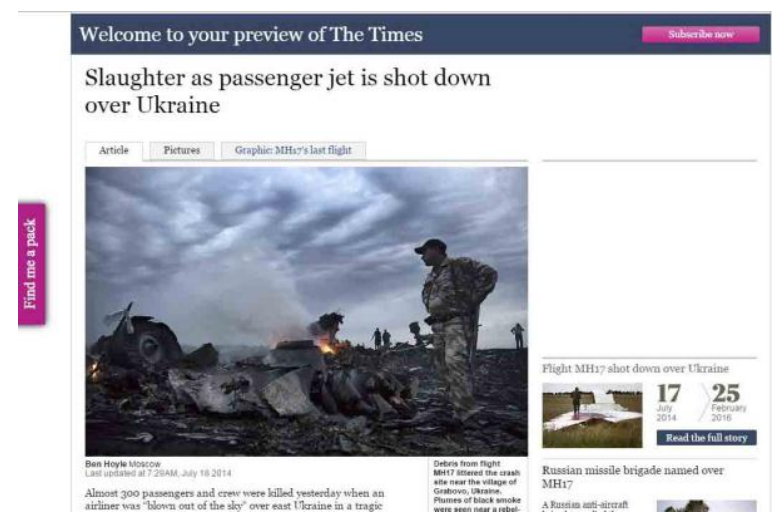

Gambar 2. Foto karya kontributor AP Photo, Dmitri Lovetsky yang sudah tayang di portal berita The Times. Gambar sudah memasuki proses editing dengan penambahan level dan contras

Fotografi jurnalistik bukan media transformasi dan metafora bidang visual akan tetapi bentuk informasi yang dikemas melalui media gambar tidak bergerak. Jika ditinjau ulang melalui tanda yang saling melengkapi unsur objek, langit di lokasi jatuhnya pesawat $\mathrm{MH}-17$ menunjukan unsur when atau kapan terjadinya insiden tersebut.

Apabila sebuah foto mendapatkan editing yang berlebihan dari objek awal sore hari atau pagi hari dimana cahaya matahari masih belum bersinar sepenuhnya, penggunaan level dan HDR yang berlebihan akan mengakibatkan langit lebih melekuk-lekuk sehingga menimbulkan interprettasi mendung. Penambahan level intensitas cahaya pada langit jika berlebihan menunjukan foto tersebut diambil pada siang hari sehingga bentuk editing yang berlebihan dapat menimbulkan subjektifitas berlebihan dan menghalangi penyampaian pesan dari sebuah bidang visual.

Unsur cerah yang berlebihan membuat pembaca atau konsumen media menjadi bertanya-tanya kapan foto itu diambil di lapangan pagi hari, siang hari, sore hari atau malam hari, cahaya langit yang over, langit biru cerah, dan seragam petugas keamanan yang mencolok sangat berbeda dengan foto asli dari Dmitri Lovetsky. Dramatisasi gambar menjadi berkurang karena proses editing yang berlebihan maka realitas makna menjadi berbelok karena tidak menggambarkan kejadian sebenarnya, kekuatan atau unsur dramatisasi sebenarnya tidak berada pada proses editing akan tetapi unsur realitas yang ada. Kamera dan pewarta foto diharapkan menjadi wakil atau mata para konsumen media yang tidak bisa melihat langsung realitas sebenarnya di lapangan untuk dihadirkan dalam medium fotografi jurnalistik.
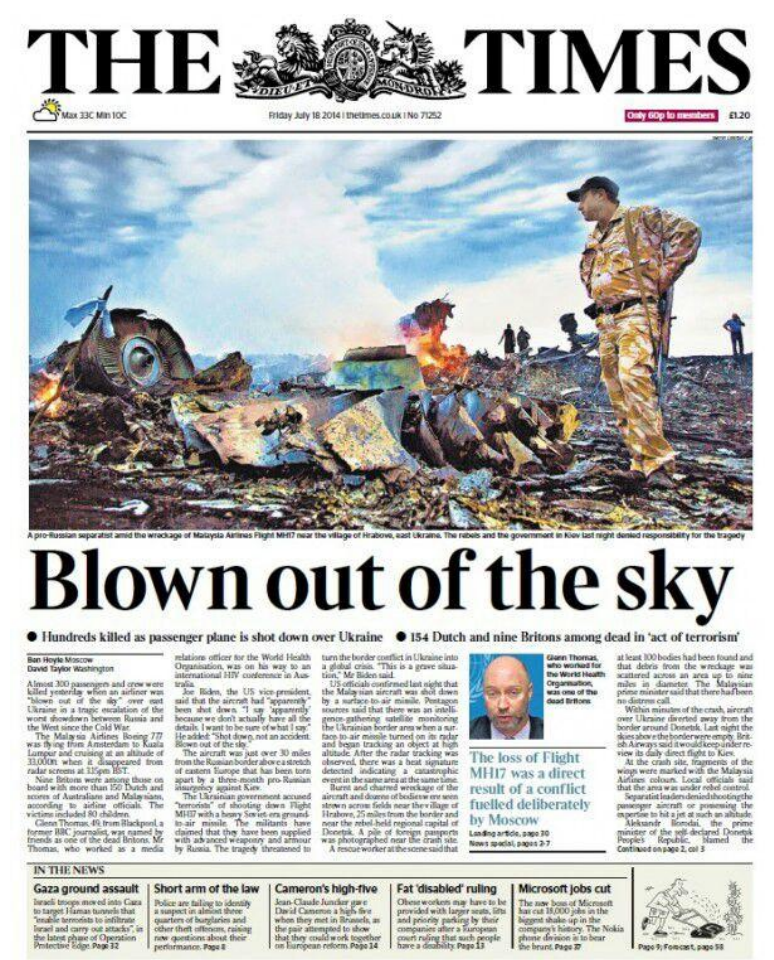

Gambar 3. Foto karya kontributor AP Photo, Dmitri Lovetsky yang dimuat dalam edisi cetak The Times. Gambar sudah mendapatkan banyak proses editing berbeda dari warna aslinya

Pada kasus kedua The Times kembali memuat foto yang tidak sesuai dari unsur realitasnya dengan memberikan sentuhan editing yang berlebihan. Puing-puing sisa kerusuhan tampak berserakan akan tetapi dengan warna yang lebih mencolok dari foto aslinya, asap sisa kebakaran terlihat lebih hitam dan menggumpal tebal sehingga terkesan kebakaran lebih besar dari kejadian aslinya. Foto karya Louisa Gouliamaki fotografer kantor berita AFP yang karyanya juga sering dirilis kembali oleh Getty Images melalui kameranya menjadi saksi untuk merekam kejadian penembakan warga sipil oleh militer di Independence Square pusat kota Kiev. Demonstrasi yang memakan banyak korban tersebut berakhir rusuh dan menelan korban jiwa karena masyarakat menolak kebijakan pemerintah Ukraina.

Gambar 4 merupakan gambar asli dari web AFP Photo/Getty Images yang sudah mendapatkan banyak proses editing berbeda dari warna aslinya dan dimuat pada The Times edisi cetak 


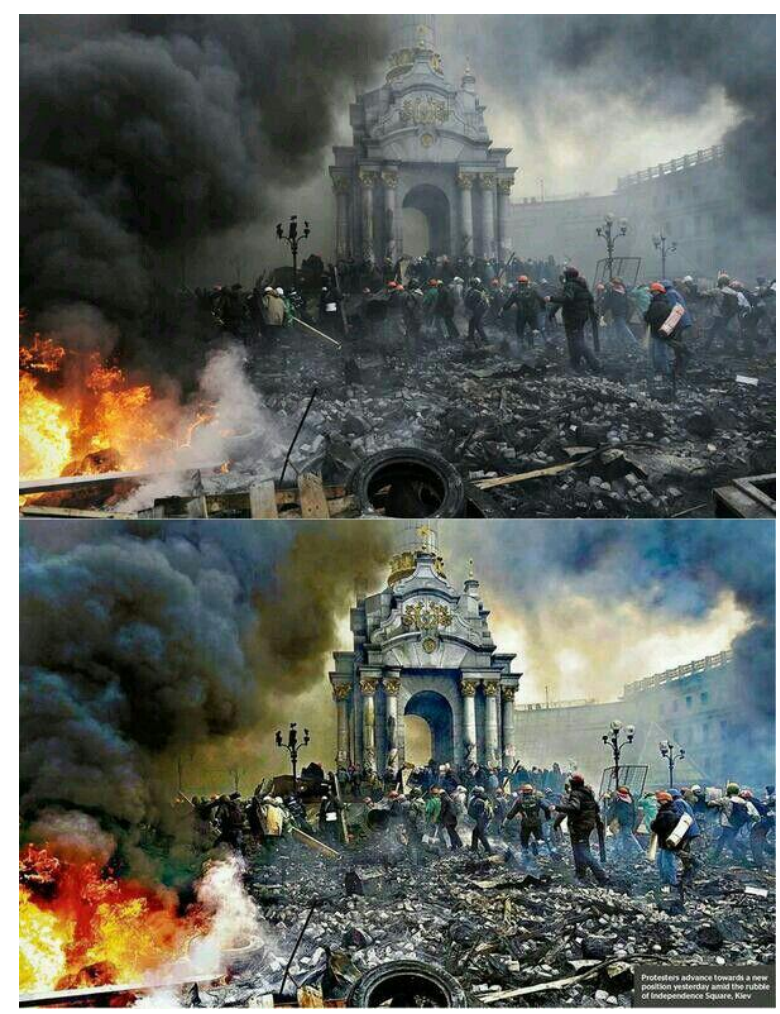

Gambar 4. Foto karya kontributor AFP Photo / Getty Images, Louisa Gouliamaki.

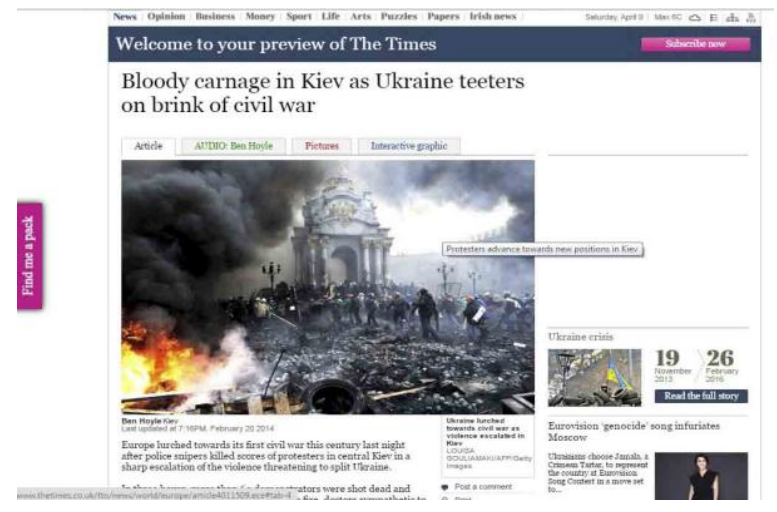

Gambar 5. Foto karya kontributor AFP / Getty Images, Louisa Gouliamaki. yang sudah tayang di portal berita The Times. Gambar sudah memasuki proses editing dengan penambahan level dan contras

Foto yang dilatarbelakangi oleh gejolak masyarakat dan berdampak pada kerusuhan memang tidak mudah untuk disajikan, satu sisi pewarta foto ingin menampilkan nilai dramatisasinya dengan memotret korban dan momen-momen tindak penganiayaan dari aparat pada demonstran, sisi lain pewarta foto ingin menampilkan sisi etika dan kemanusiaannya dengan tidak menampilkan foto yang berdarah-darah walaupun merupakan realitas sebenarnya di lapangan. Foto yang baik adalah sebuah karya visual yang dapat membangkitkan emosi khalayak yang melihatnya tanpa tidak melebih-lebihkan atau mengurangi unsur realitas yang ada.

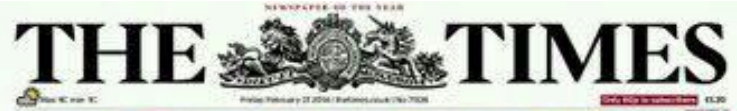
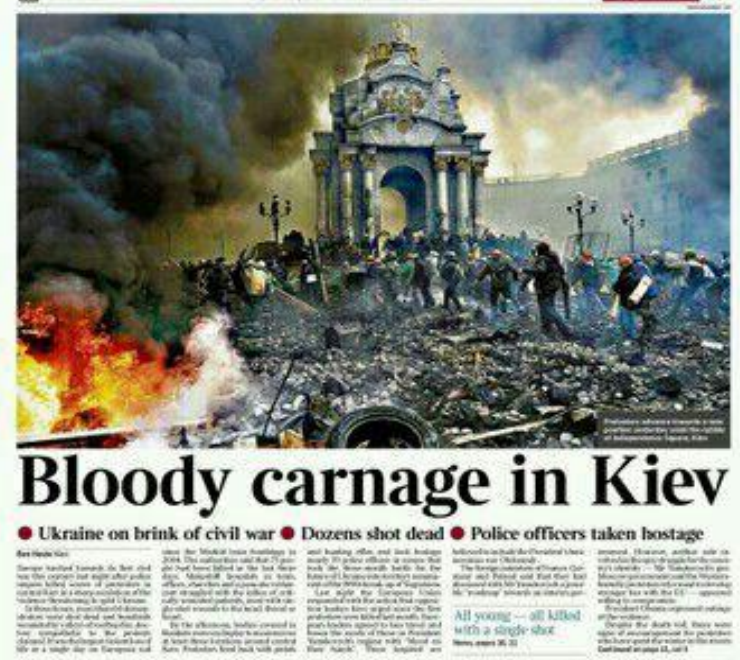

Prepare for interest rate rise next spring, homeowners told

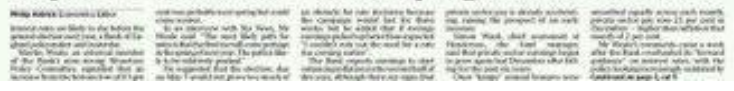

Gambar 6. Foto karya kontributor. AFP / Getty Images, Louisa Gouliamaki yang dimuat dalam edisi cetak The Times. Gambar sudah mendapatkan banyak proses editing berbeda dari warna aslinya

Fotografi jurnalistik akan tetap berdiri pada hakekat penciptaanya sebagai media informasi dengan menampilkan visual yang mengedepankan unsur realitas, tidak menerka-nerka secara subjektif akan pesan yang disampaikan bukan pula abstrak dan surealis seperti yang tertuang dalam fotografi ekspresi, fine art, fotografi kontemporer atau foto konsep yang lainya. Fotografi sendiri merupakan sebuah image tanpa kode, bahwa ini bukanlah sebuah copy dari realitas tetapi sesutu yang memang berasal dari realitas yang telah lalu yang memiliki sebuah kekuatan pembuktian (Barthes 1982, 89).

Kekuatan foto jurnalistik tidak hanya dilihat dari visual yang dapat menimbulkan emosi bagi penglihatnya, akan tetapi foto yang belum dilengkapi caption-pun dapat menyimbolkan kepada penglihatnya apa yang sedang terjadi di luar sana meskipun foto tersebut benar-benar belum memiliki caption dan judul. Disaat seorang pewarta foto terjun di lapangan tentunya tidak mengabaikan teknis gambar dan lebih mengutamakan momentum akan tetapi masyarakat saat ini sudah digiring untuk lebih sadar media, masyarakat mulai memilih dari media satu ke media lain bentuk keindahan foto dan keakuratan di balik berita foto tersebut sehingga media banyak yang mengemas foto menjadi sebuah rubrik tersendiri ditambah lagi dengan keprofesionalitasan pewarta foto untuk mengemas karyanya dengan lebih memperhatikan nilai-nilai estetika. 
Foto tidak hanya bersifat informatif, estetik, dan komunikatif akan tetapi di masa sekarang ini foto juga menjadi karakter setiap media akan kualitas setiap pewarta foto dan redaktur fotonya, banyak sekali konsumen media yang membeli sebuah media cetak untuk melihat rubrik foto dan berita foto terlebih dahulu daripada membaca berita tulisnya. Foto jurnalistik akan selalu hadir untuk saling memperkuat tulisan bahkan lebih kuat dari tulisan beritanya dan tidak hanya menjadi ilustrasi sebuah berita saja.

Tujuan yang hakiki dari fotografi ialah komunikasi. Tidak banyak orang membuat gambar hanya untuk menyenangkan diri sendiri. Kebanyakan orang memotret karena ingin dilihat orang lain. "Kita ingin menjelaskan, membidik, menghibur, mengungkapkan pengalaman pada kepada orang lain. Gambar ialah sarana bagi juru foto, seperti kata- kata ialah sarana bagi penulis untuk mengungkapkan apa yang diinginkan" (Soelarko, 1993:10).

Media memiliki karakter dari setiap pesan yang akan disampaikan kepada khalayak dimana realitas yang digambarkan oleh frame memberi realitas kepada golongan pemberi kebijakan atas wajah yang dialami oleh masyarakat yang dinaungi oleh kelompok sosial. Bencana alam, unjuk rasa, kelaparan, perang dan kemiskinan menjadi wajah tersendiri untuk disajikan atas realitas yang ada sebagai tontonan untuk realitas individu ke arah yang lebih konkret untuk disajikan

Dalam proses komunikasi massa, peran media massa sangat penting. Media massa sebagai sebuah sarana atau media dimana pesan akan disalurkan dan disebarluaskan pada khalayak. Media massa yaitu media komunikasi yang mampu menimbulkan keserempakan, dalam arti khalayak dalam jumlah yang relatif banyak secara bersama-sama pada saat yang sama memperhatikan pesan yang dikomunikasikan melalui media tersebut, misalnya surat kabar, radio siaran, televisi siaran, dan sebagainya (Effendy, 1989:217). Pada intinya fotografi jurnalistik merupakan proses penyampaian pesan kepada khalayak dengan menggunakan media visual, sehingga media dalam melakukan proses penyampaian pesan visual yang dapat dinilai subjektif harus tepat sasaran (Widjaja, 1986: 32).

Sebuah foto jurnalistik akan menjadi arsip yang memiliki kebohongan sepanjang masa jika dari realitasnya dan fotonya tidak memiliki kesamaan karena tujuan utama fotografi jurnalistik merupakan sarana pendokumentasian yang mengandung nilai berita untuk disiarkan kepada khalayak. Susan Sontag berpendapat fotografi melakukan dua hal sekaligus. Pertama, menentukan juga memenjarakan dan memalsukan waktu. Kedua mensertifikasi dan menolak pengalaman. Ini adalah sebuah ketundukan kepada dan sebuah serangan kepada realitas, ini adalah alat untuk menyesuaikan realitas dan alat untuk membuatnya usang (Hutcheon 1989, 122).

Dalam perspektif ruang-ruang postmodern hiperealitas tentang imajinasi visual pada foto menjadi sangat signifikan dalam citra media. Jurnalisme secara umum tidak lagi menghadirkan rangkaian konstruksi fakta, tetapi menghadirkan realitas dalam konteks seduksi dan apakah sebuah materi kemudian memiliki sebuah mind game sebagai sebuah pemenuh hasrat manusia; di mana ini adalah sebuah bahan tontonan yang hanya melepaskan sebuah hasrat informasi; yang membuat para konsumen tidak membaca fakta jurnalistik tetapi justru merasakan konstruksi realitas peristiwa.

Kehidupan dalam berita sebagai sebuah bahan atau hasrat yang menghadirkan seduksi tertentu, sebuah ilusi dalam visualisasi. Sebuah kesenangan yang diperoleh dari sebuah kejadian asli yang seharusnya bukanlah dipandang sebagai tontonan tetapi sebagai sebuah informasi. Dan pada ujungnya hiperealitas sebagai sebuah hubungan referensial hanyalah menghubungkan simbol-simbol dengan ruang ilusi. Permainan fragmentasi faktafakta dalam konstruksi hiperealitas telah menghadirkan ruang ilusi tertentu dalam potonganpotongan dan dalam parodi-parodi tertentu yang oleh Hutcheon dikatakan banyak berisi sebuah ironisasi yang kuat yang terus tumbuh hingga refernsial realitas dan tanda hilang dan menjadi sebuah parodi yang tersusun kompleks dari potongan simulasi dan bersifat surealis ketimbang realis.

Pada kajian semiotika foto jurnalistik elemenelemen objek yang terekam bisa menjadi pengurai oleh khalayak untuk menginterpretasikan informasi atau dan nilai berita yang akan disampaikan, tidak perlu penampilan visual yang menarik dengan editing salon foto yang memanjakan mata dan memberi kesan foto tersebut sangat indah dipandang mata akan tetapi menyampaikan makna tentang kesedihan seperti perang, insiden, bencana bahkan musibah kecelakaan. Tanda merupakan segala sesuatu yang bisa menggantikan atau mewakili kehadiran (keberadaan) sesuatu yang lain. Semua bisa diambil sebagai tanda (Eco 1979, 7). 
Masyarakat pada saat ini sudah mulai cerdas akan menilai sebuah kualitas pemberitaan hingga kualitas sajian foto pada sebuah media, celah tersebut menjadi introspeksi bagi redaktur foto bagaimana memuat foto yang benar berdasarkan realitas yang terjadi dan tidak melakukan editing yang berlebihan karena akan menjadi interpretasi yang sangat subjektif bagi konsumen media dalam memahami suatu pesan. Tanda mempunyai sebuah hubungan dalam konstruksi kebohongan. Eco menganggap semiotik sebagai sebuah kajian tanda-sebuah teori tentang kebohongan, dimana prinsipnya menurut Eco sesuatu yang tidak bisa digunakan untuk berbohong juga tidak bisa menyatakan kebenaran itu sendiri (Eco 1979, 7).

\section{Simpulan}

Penyampaian fakta melalui media visual memegang peranan ampuh untuk membangkitkan emosi pembaca media, dalam hal ini foto jurnalistik menjadi duta yang harus menyampaikan sesuai fakta setelah infografis pada sebuah media online, surat kabar harian dan tayangan di TV. Foto jurnalistik yang baik adalah foto yang menyampaikan realitas kejadian sesungguhnya melalui kamera dan pewarta fotonya sebagai wakil dari konsumen media di rumah.

Realitas tersebut tidak akan berujung pada nilai informasi jika menampilkan foto yang tidak sesuai dengan ralitas sesungguhnya. Banyaknya editing pada sebuah karya foto jurnalistik dapat mengakibatkan pemahaman yang multi tafsir, seperti contohnya editing langit yang mendung menjadi biru cerah dapat membelokan khalayak untuk mengetahui waktu kejadian berita tersebut karena khalayak akan menduga kejadian tersebut siang hari padahal kejadian sesungguhnya terjadi pada pagihari atau sore hari.

Redaktur foto, pewarta foto, dan media harus lebih bijaksana dalam memuat fotonya, tidak selamanya foto yang mendapatkan editing berlebihan menjadi bagus dan dramatikal. Foto jurnalistik yang baik merupakan bahasa gambar yang menyampaikan realitas sebagai kabar untuk masyarakat agar mendapatkan wawasan sebagai bentuk pertanggungjawaban untuk mengedukasi masyarakat.

\section{Daftar Pustaka}

A.W.Widjaja. 1986. Peranan Motivasi Dalam Kepemimpinan, Bandung Edisi Pertama, Cetakan Pertama. Cv. Akademika Pressindo

Barthes, Roland. 1982. America Lucida; Reflection On Photography. New York: Hill And Wang.

Eco, Umberto. 1979. A Theory Of Semiotics. Bloomington: Indiana University Press

Efendy, Onong Uchaja. (2003). Ilmu Komunikasi Teori dan Prakterk, Remaja Rosdakarya, Bandung.

Feininger, Andreas. (1996). Unsur Utama Fotografi, Dahara Prize. Semarang.

Hutcheon, Linda. 1989. The Politics of Postmodernism. London: Routledge.

Kripendrof, K, 1993. Analisis Isi Pengantar Teori dan Metodologi, Raja Grafindo, Persada. Jakarta.

Soelarko, R.M. (1993), Unsur Utama Fotografi, Dahana Prize, Semarang. 